Archived version from NCDOCKS Institutional Repository http://libres.uncg.edu/ir/asu/

\title{
Appalachlyan
}

$\overline{B \text { O O N E, N O R T H C A R O L I N A }}$

\section{Sustaining School Hand Washing And Water Treatment Programmes: Lessons Learned And To Be Learned}

\author{
By: SHADI SABOORI, ALEX MWAKI, SARAH E. PORTER, BEN OKECH, MATTHEW C. \\ FREEMAN, and RICHARD D. RHEINGANS
}

\begin{abstract}
In Nyanza Province, Kenya, a sustainability evaluation of 55 pilot primary schools 2.5 years after the implementation of the Safe Water System (SWS) intervention revealed that programme activities were not successfully sustained in any of the schools visited. The most common criterion met was drinking water provision. We identified six enabling environment domains: financial capacity; accountability; technical feasibility and availability; community support; school leadership and management; and student engagement. While these domains pertain to the sustaining of the SWS activities in schools, they are likely to be applicable in creating an enabling environment and serve as proxy indicators for other school water, sanitation, and hygiene initiatives as well.
\end{abstract}

Saboori S, Mwaki A, Porter SE, Okech B, Freeman MC and Rheingans RD. 2011. Sustaining School Hand Washing and Water Treatment Programs: Lessons Learned and to be Learned. Waterlines. pp.298-311. ISSN 0262-8104. Version of record available at: http://www.developmentbookshelf.com/doi abs/10.3362/1756-3488.2011.040 


\title{
Sustaining school hand washing and water treatment programmes: Lessons learned and to be learned
}

\author{
SHADI SABOORI, ALEX MWAKI, SARAH E. PORTER, \\ BEN OKECH, MATTHEW C. FREEMAN, and \\ RICHARD D. RHEINGANS
}

In Nyanza Province, Kenya, a sustainability evaluation of 55 pilot primary schools 2.5 years after the implementation of the Safe Water System (SWS) intervention revealed that programme activities were not successfully sustained in any of the schools visited. The most common criterion met was drinking water provision.

We identified six enabling environment domains: financial capacity; accountability; technical feasibility and availability; community support; school leadership and management; and student engagement. While these domains pertain to the sustaining of the SWS activities in schools, they are likely to be applicable in creating an enabling environment and serve as proxy indicators for other school water, sanitation, and hygiene initiatives as well.

Keywords: school sanitation, hand washing with soap, enabling environment, recurrent costs

There has recently been increased attention on improving access to WASH in schools
THERE HAS RECENTLY BEEN increased attention on improving access to safe water provision, sanitation, and hygiene education (WASH) in schools (UNICEF, 2010). Data are sparse, but best estimates put access to water in schools in developing countries at 46 per cent and sufficient access to sanitation at 37 per cent (UNICEF, 2008). Increased funding is necessary to improve school WASH access, but a critical challenge is the development of sustainable programmes in order to maximize efforts and available resources (IRC and UNICEF, 2005). In the absence of long-term sustainability, the impact and cost-effectiveness of these investments will be limited.

Among successful school-based WASH programmes, there is little understanding of what factors stimulate long-term programme

Shadi Saboori and Sarah Porter are with the Center for Global Safe Water, Hubert Department of Global Health, Rollins School of Public Health, Emory University, Atlanta, USA; Alex Mwaki and Ben Okech are with CARE Kenya; Matthew Freeman is with the Center for Global Safe Water, and London School of Hygiene and Tropical Medicine; and Richard D. Rheingans is with the Center for Global Safe Water and Department of Environmental and Global Health, University of Florida, Gainesville, USA. 
Few school WASH programmes complete project evaluations following completion

outcomes (Snel, 2004). Few school WASH programmes complete project evaluations following completion of software or hardware delivery. In India, four years after programme implementation, authors found that water and sanitation hardware was better maintained in intervention schools than in control schools; however, some measures of pupil hygiene and sanitation behaviours were not always different, and soap was rarely provided in any school (Mathew et al., 2009). A report seeking to identify predictors of sustainability in 100 Kenyan schools highlighted the need for an established supply chain, budget, and institutional support to ensure necessary WASH items and school support could be continuously provided (Njuguna et al., 2007). Beyond these assessments, we are unaware of other school WASH sustainability evaluations that have been carried out to date, underscoring the need for more learning surrounding this issue.

Monitoring for project endpoints over time, such as continued beneficiary use, knowledge, and health is important to assess programme impact, but it is rarely feasible given the limited financial and technical capacity of project communities (Harnmeijer and Sutton, 1993). An alternative to this approach is to emphasize the monitoring of 'leading indicators' of sustainability, such as the school's financial capacity and accountability mechanisms. In this paper, we discuss results from a pilot school-based WASH programme in western Kenya and use the findings to propose a set of domains that characterize an enabling environment for sustained school WASH infrastructure and activities.

\section{Project background}

CARE Kenya implemented a Safe Water System (SWS) promotion programme in 60 schools in rural Nyanza Province, Kenya

From February 2005 to January 2006, as part of a pilot programme to reduce diarrhoeal disease in pupils, CARE Kenya implemented a Safe Water System (SWS) promotion programme in 60 schools in rural Nyanza Province, Kenya. The SWS consists of the provision of point-of-use drinking water treatment with sodium hypochlorite solution, drinking water and hand-washing water storage containers with a narrow mouth and tap to prevent contamination, and hygiene education (CDC, 2000). CARE employed a trainer of the trainer model in which teachers are trained as 'SWS patrons' to oversee SWS activities, including the formation of school health clubs and the promotion of message transfer to other children and parents.

An evaluation of nine randomly selected project schools, carried out in February 2006, found that all schools (100 per cent) had functioning drinking water and hand-washing containers; eight schools (89 per cent) had drinking water available the day of the site visit; seven schools (78 per cent) had detectable chlorine residual; 
and one school (11 per cent) had soap available for students (O'Reilly et al., 2008).

\section{Methods}

Two and a half years after completion, a sustainability assessment was conducted in the same 60 pilot schools
In April 2008, two and a half years after completion of pilot programme activities, a sustainability assessment was conducted in the same 60 pilot schools. The sustainability assessment had three specific objectives:

- Determine if the schools were continuing with the key components of the intervention, including presence of hardware and evidence of continued activities.

- Describe components of an enabling environment that contributes to a successfully sustained intervention.

- Develop recommendations for continued programme improvement.

Prior to data collection, we identified key activities deemed critical for sustained impact. A school in which the intervention was 'sustained' would carry out each of these activities on a regular basis. Additionally, we identified characteristics of an enabling environment where sustained behaviours would occur. These preconditions, such as availability of funds for recurrent costs, are necessary for fostering key activities such as soap provision for hand washing. Key activities and preconditions are outlined in Table 1 . The primary data analysis was an assessment of the frequency of the main activities and the enabling conditions.

Data were collected from 55 of the original 60 pilot schools in the Suba, Homa Bay, and Rachuonyo Districts of Nyanza Province, Kenya. Five of the schools were excluded for logistical reasons because they were difficult to access at the start of the heavier rainy season. Schools were visited by Meshack Odhiambo and Stephen Kimo, project supervisors from Great Lakes University of Kisumu. Permission to conduct the evaluation was given by the Area Education Officers for

Table 1. Preconditions and key activities necessary for sustaining the Safe Water System (SWS)

\begin{tabular}{ll}
\hline Preconditions for sustained project activities & Key activities necessary for sustained project impact \\
\hline Availability of an accessible water source \\
Availability of funds for recurrent costs \\
Repurchase of water treatment products \\
$\begin{array}{l}\text { Purchase of soap } \\
\text { Repair of containers }\end{array}$
\end{tabular}


each district, but individual schools were not notified that they would be visited.

At each school, we employed a quantitative and open-ended structured interview with either the head teacher or one of the SWS patrons regarding school characteristics, key activity indicators, preconditions, and perceived barriers surrounding each of the four SWS activities. In addition, researchers conducted direct observations of the condition of water storage containers, presence of water in the containers, and presence of soap. Finally, stored drinking water was tested for residual chlorine in schools that reported treating their water on the day of the visit using the orthotolidine (OTO) method $<$ www.aquachem.com $>$.

Following assessment of preconditions for sustained use and the four key outcomes that determined sustained use, the most successful schools were compared to determine which preconditions for sustained use proved critical for sustained activities. Since the number of successful schools was small, comparisons were assessed using descriptive statistics. After reviewing the findings from the school visits, we conducted participatory discussions with key implementing partners to identify key barriers and enablers of sustaining WASH in schools. These factors were used to develop a model of the enabling environment.

\section{Results}

\section{Sustained WASH facilities}

Only three schools (5 per cent) had detectable levels of free chlorine in their drinking water provided to pupils

Provision of soap was observed near the hand-washing containers at only one school
Drinking water provision and treatment. On the day of the site visit, 20 schools (36 per cent) reported providing drinking water, and 29 schools (53 per cent) were observed to have provided drinking water (Table 2). A total of 11 schools (20 per cent) reported treating their drinking water and 24 schools (44 per cent) reported having water treatment products at the school; however, only three schools (5 per cent) had detectable levels of free chlorine in their drinking water provided to pupils.

Hand-washing water and soap provision. A total of 10 schools (18 per cent) reported providing hand-washing water, and nine schools (16 per cent) were observed to have provided hand-washing water on the day of the evaluation (Table 2). Provision of hand-washing soap was observed near the hand-washing containers at only one school ( 2 per cent), although three schools (6 per cent) reported always providing soap for hand washing. The school that provided soap for hand washing did not have drinking or hand-washing water. 
Table 2. Indicators for sustained use of the Safe Water System (SWS) in 55 project schools

\begin{tabular}{|c|c|c|c|}
\hline Indicators for sustained SWS use & Means of verification & $n$ & $\%$ \\
\hline \multirow{2}{*}{$\begin{array}{l}\text { Provision of drinking water in safe storage } \\
\text { containers }\end{array}$} & Reported providing drinking water on day of visit & 20 & 36 \\
\hline & Drinking water observed on day of visit & 29 & 53 \\
\hline \multirow[t]{2}{*}{ Treatment of drinking water with chlorine } & Reported treating drinking water on day of visit & 11 & 20 \\
\hline & Confirmed by measured chlorine residual & 3 & 5 \\
\hline \multirow[t]{2}{*}{ Provision of water for hand washing } & $\begin{array}{l}\text { Reported providing hand-washing water on } \\
\text { day of visit }\end{array}$ & 10 & 18 \\
\hline & Hand-washing water observed on day of visit & 9 & 16 \\
\hline \multirow[t]{2}{*}{ Provision of soap for hand washing } & Reported always providing soap for hand-washing & 3 & 6 \\
\hline & Soap for hand washing observed on day of visit & 1 & 2 \\
\hline
\end{tabular}

The least sustained SWS components were drinking water treatment and hand-washing soap provision
Presence of multiple components. Of the 55 schools in this assessment, no schools had all four of the necessary components in place on the day of the visit, while 25 schools ( 45 per cent) did not have any of the four components in place (data not shown). All schools that provided hand-washing water also provided drinking water. The least sustained SWS components were drinking water treatment and hand-washing soap provision, and no school had both components on the day of the visit.

\section{Preconditions for sustained use}

Water source availability and access. The majority of schools (88 per cent) reported relying on an improved source in the rainy season, but only 26 schools (47 per cent) reported dry season improved sources (Table 3). A total of 50 schools (91 per cent) in the rainy season and 39 schools (71 per cent) in the dry season were within $1 \mathrm{~km}$ of their primary water source. When the distance to the school's rainy or dry season water source was beyond $0.5 \mathrm{~km}$, provision of both drinking and hand-washing water tended to decrease.

Repair of containers. Most schools (56 per cent) reported experiencing breakage of containers or taps (Table 3). Respondents from 20 (37 per cent) schools reported knowing where to purchase replacement parts, but only six schools (11 per cent) reported replacing them.

Repurchase of water treatment products and purchase of soap. Just over half of schools (53 per cent) reported allocating funds for water treatment, and 23 schools (42 per cent) reported allocating funds for soap (Table 3). The majority of schools (75 per cent) reported purchasing additional water treatment products in addition to the free supply 
Table 3. Indicators for the preconditions necessary for the Safe Water System (SWS) in 55 pilot schools, Nyanza Province, Kenya

\begin{tabular}{|c|c|c|c|}
\hline Preconditions for sustained activities & Means of verification & $n$ & $\%$ \\
\hline \multirow[t]{2}{*}{ Availability of an accessible water source } & Rainy season source $<1 \mathrm{~km}$ & 50 & 91 \\
\hline & Dry season source $<1 \mathrm{~km}$ & 39 & 71 \\
\hline \multirow[t]{5}{*}{ Repair of containers and taps } & School reports water container has broken in past year & 15 & 27 \\
\hline & $\begin{array}{l}\text { Of those, school reports broken container has been } \\
\text { replaced in the past year }\end{array}$ & 3 & 20 \\
\hline & School reports tap has broken in past year & 28 & 51 \\
\hline & $\begin{array}{l}\text { Of those, school reports broken tap has been replaced in } \\
\text { the past year }\end{array}$ & 5 & 18 \\
\hline & School has knowledge of where to find replacement parts & 20 & 36 \\
\hline \multirow[t]{3}{*}{ Repurchase of water treatment products } & School reports currently having water treatment products & 24 & 44 \\
\hline & $\begin{array}{l}\text { School reports cost or lack of funds as reason for currently } \\
\text { not having water treatment products }\end{array}$ & 15 & 27 \\
\hline & $\begin{array}{l}\text { School reports repurchasing water treatment products } \\
\text { after initial project inputs }\end{array}$ & 41 & 75 \\
\hline \multirow[t]{2}{*}{ Purchase of soap } & School reports hand-washing soap is 'always' provided & 3 & 5 \\
\hline & $\begin{array}{l}\text { School reports cost or lack of funds as reason why soap is } \\
\text { not always purchased }\end{array}$ & 33 & 60 \\
\hline \multirow[t]{2}{*}{$\begin{array}{l}\text { Teachers monitoring and promoting } \\
\text { key activities }\end{array}$} & School has at least one SWS patron remaining & 39 & 71 \\
\hline & School has trained additional SWS patrons & 36 & 65 \\
\hline $\begin{array}{l}\text { School Health Club (SHC) or other } \\
\text { mechanism to engage children }\end{array}$ & School reports active SHC & 9 & 16 \\
\hline \multirow[t]{5}{*}{ Availability of funds for recurrent costs } & School reports budgeting for WASH activities and hardware & 42 & 76 \\
\hline & School reports budgeting for water treatment products & 29 & 53 \\
\hline & School reports budgeting for soap & 23 & 42 \\
\hline & School reports budgeting for purchase of containers & 5 & 9 \\
\hline & School reports budgeting for infrastructure repairs & 13 & 24 \\
\hline
\end{tabular}

that was given by the project. Of the 14 schools that did not purchase additional treatment products, eight (57 per cent) reported that water treatment was not considered a high priority.

Teacher monitoring and promotion of key activities. Teacher transfer is common in Kenyan public schools. As a result, 18 schools (33 per cent) reported having both of the original SWS patrons remaining in the school, while 22 schools (40 per cent) had one, and 15 schools (27 per cent) had none (Table 3). Of those schools that lost a patron, 70 per cent of schools reported involving new teachers in the SWS activities. 


\section{Cost was cited as a barrier to providing water treatment products and soap}

School Health Clubs (SHC) or other mechanism used to engage children. Only nine schools (16 per cent) reported having active SHCs (Table 3 ). However, as the term 'active' was not well defined in the survey, this indicator was not adequately assessed during the evaluation.

Availability of funds for recurrent costs. Cost was cited by 15 schools (27 per cent) as a barrier to providing water treatment products and by 33 schools (61 per cent) as a barrier for providing soap (Table 3 ).

\section{Characteristics of the most successful schools}

Of the 55 pilot schools evaluated, one school provided soap but did not provide the other three key components of the SWS (data not shown). Two schools had hand-washing water, drinking water, and drinking water containers with measurable chlorine residual on the day of the evaluation and were considered the most successful of the sample. They were compared with one another to determine similarities.

Both schools reported having rainwater available during the rainy season within the school compound, and always treating the drinking water. Each school had a designated person responsible for treating water: one school designated pupils while the other designated SWS patrons. Both schools reported repurchasing water treatment products. Despite the success of treating their drinking water, neither school had soap on the day the survey was conducted. The reason given by one of the schools for lack of soap provision was that it was stolen from the school grounds.

The two successful schools had a high level of institutional support; at least one of the original trained patrons was still at the school and both reported involving new teachers in addition to the original trained patrons in SWS activities. The school management committees (SMCs) were reported active and reported to carry out WASH-related activities, either through community education, latrine construction, or purchasing WASH supplies. Both schools reported budgeting for WASH inputs and activities, including using funds to buy water treatment products and parental contributions for SWS activities.

In addition, both schools cited observed health benefits as one of the factors influencing continuation of SWS activities. One school in particular was actively monitoring its pupils' health status by keeping a health monitoring book and graphing pupils' absenteeism due to illness in order to track improvements.

Nine other schools in the assessment shared the same traits described above, and the majority of those schools fulfilled either one or none of the criteria for success. 


\section{Discussion}

Based on the four initial criteria, the SWS activities were not successfully sustained in any of the 55 schools visited. The most common criterion met was drinking water provision; the other criteria were less common and took place in a minority of schools. While a number of common characteristics required for schools to be successful in sustaining the SWS activities were highlighted for the two most successful schools, nine less successful schools shared the same traits. Thus, while these identified traits are informative, they are clearly not adequate alone to enable sustainability.

\section{Promoting an 'enabling environment' and recommendations for the future}

There are many factors necessary for fostering an environment in which schools continue key WASH activities

There are many factors necessary for fostering an environment in which schools continue key WASH activities. Using the quantitative findings from school visits and further discussions with key stakeholders, we identified six domains within this 'enabling environment': financial capacity; accountability; technical feasibility and availability; community support; school leadership and management; and student engagement. We also developed recommendations specific to each domain concerning how implementers can foster sustained SWS activities in schools. While these domains pertain to the sustainability of SWS in schools, they are likely to be important in creating an enabling environment for other school WASH improvements as well.

Financial capacity. A system of school funding that allows for establishment, maintenance, repair, and repurchase of needed inputs is essential for the long-term success of any WASH project. Insufficient funds were often mentioned as the reason for the cessation of key SWS activities, as school resources allotted by the Government of Kenya for WASH activities are extremely limited and compete with other priorities. The entire annual allocation for 'water, electricity, and conservancy' currently in Kenya is 10 Kenyan shillings (KES) (US\$0.12) per pupil per year, which is inadequate for repurchase of consumable WASH goods for the entire school year (Sawamura and Sifuna, 2008). SWASH+ partners conducted a costing analysis and determined that a minimum increase of KES33 per child per year is required to cover water treatment, hand-washing soap, and basic latrine cleaning supplies.

Given that inadequate government funding is often a reality in resource-poor settings, programme implementers and beneficiaries need to anticipate recurrent costs and establish funding to support the SWS. Establishing processes for funding SWS activities should be 


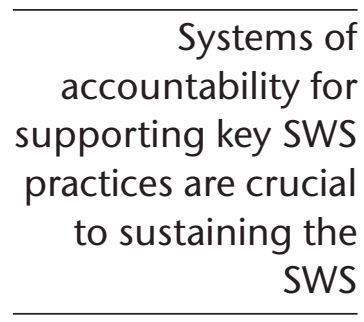

Systems of supporting key sws practices are crucial SWS a significant component of the training that head teachers, patrons, and the SMCs receive at the project outset.

Accountability. There are three components of accountability: how government officials, such as the Ministry of Education, are held accountable by their constituents to provide adequate funding and oversight for WASH activities in schools; how the school administration is held accountable for provision of WASH activities; and how school stakeholders (children, teachers, parents) are held responsible for WASH access at school. Schools and their head teachers are often accountable to communities and government authorities for school metrics relating to condition of classrooms, pupil attendance, and educational performance. However, school administration is often not held accountable for provision of safe drinking water, hand-washing facilities and soap, or adequate and clean sanitation facilities. Regular monitoring and performance requirements for WASH activities may provide incentives for schools to prioritize these items. When possible, government officers should integrate SWS activities into their regular school monitoring evaluations in order to strengthen impetus for schools to maintain SWS activities.

At the school level, systems of accountability for supporting key SWS practices are crucial to sustaining the SWS. While school duty rosters were not assessed in this trial, anecdotal evidence from the schools visited indicated that the schools with no defined systems for completion and oversight of water provision, latrine maintenance, and water treatment were less likely to complete these activities regularly. Each school needs a transparent and well-defined system in place to ensure all WASH activities take place in a timely manner. A well-defined system should establish accountability using rosters detailing teacher and student responsibilities. Daily responsibilities should include water collection, soap provision, water treatment, and cleaning of the containers.

Technical feasibility and availability. Access to affordable replacement parts is essential for ongoing repairs, but sometimes it is beyond the control of the school. The technical specifics of water containers, tap, and soap are often varied across a particular geographic region and may evolve over the life cycle of a project. District- or province-wide implementation with standardized technologies would create a demand and incentive for supply chain creation. Moving towards standardization of design options, whether this means a single option or several, may reduce costs, increase ease of use, facilitate systematic training, promote supply chain availability, and facilitate systematic monitoring.

Common problems in pilot schools resulting from inappropriate technology included use of unstable stands for hand-washing 
Schools often reported that they do not know where to find repair services or replacement parts

Headmasters reported that the community was supportive of the SWS activities

\footnotetext{
Sustainability at scale may be increased through standardized roles and responsibilities of school level activities
}

containers, decommissioning of entire hand-washing containers due to a single broken tap, inability to replace the plastic taps provided, and inability to prevent theft of bar soap. Schools often reported that they do not know where to find repair services or replacement parts, or that the cost of containers being provided to schools were too expensive for repurchase.

Hardware components should be selected with attention to ease and cost of repair and replacement. The implementing organization may also establish a linkage between the manufacturers and local vendors for the hardware needed to ensure that local vendors carry necessary hardware components and schools know where to obtain supplies. Targeted efforts to work with specific suppliers of containers, treatment supplies, and soap can ensure local access to project inputs.

Additionally, if a school does not have regular access to a nearby water source, the SWS intervention is not recommended because water treatment and hand washing are unlikely to be sustained. The focus should be shifted toward improving water access.

Community support. In many of the schools visited, headmasters reported that the community was supportive of the SWS activities, and that in some cases pupils insisted on taking treated water home. This suggests that when the community has a stake in the continuing function of the SWS in schools, the pressure to sustain SWS components may encourage the head teacher and staff to ensure the system functions continuously.

At the community level, implementers should facilitate activities that encourage community interest and backing. These may include scheduling parent-teacher days to share information on SWS activities, or organization of competitions in which SHCs of different schools can present poems, skits, or other educational performances on the importance of the SWS. At the district level, policies should ensure that funding of community water improvements, whether initially NGO or publicly funded, extend to include school WASH improvements as well.

School leadership and management. The level of involvement and support in the SWS activities by the head teacher of the school can affect the level of commitment by teachers and community stakeholders. Strong management will involve budgeting properly for SWS activities and maintenance, developing a defined daily system surrounding SWS activities for teachers and students to perform, ensuring this system is being followed, and working to involve the school and community in SWS activities. Sustainability at scale may be increased through creation of standardized roles and responsibilities 


\section{Educational campaigns around WASH behaviours are more successful when pupils are engaged}

of school level activities, which could be incorporated into school management guidelines and training.

In order to increase the level of activity and initiative around the SWS, implementers should identify SWS patrons in a participatory manner. Programmes should identify the motivators and barriers for head teacher involvement in the proposed activities and receive programme buy-in from the school leadership before project implementation. Additionally, patrons must be encouraged and given specific tools on how to engage pupils and other teachers in SWS-related activities and messages.

Student engagement. Students play a crucial role in sustaining school WASH projects as they are often responsible for carrying out daily SWS tasks and creating demand and expectations for the availability of safe drinking water and hand-washing facilities. Efforts to identify, promote, and institutionalize vibrant student participation through health clubs or additional child-centred activities may strengthen participation (Sidibe and Curtis, 2007). Educational campaigns around WASH behaviours are more successful when pupils are engaged in a structured and specific manner (Onyango-Ouma et al., 2005; Bowen et al., 2007). While the participation and engagement have to happen at the school level, institutional and policy changes may be needed to make vibrant health clubs the norm.

\section{Applying lessons learned}

Following the sustainability assessment, the resulting recommendations and lessons learned were then applied to a separate ongoing trial involving SWS components in Nyanza Province, Kenya. These recommendations may be applicable for other geographic, cultural, and economic contexts. Table 4 details a selection of potential solutions that were generated in response to the sustainability issues discussed.

Several solutions have been implemented to date including piloting the use of soapy water solution in place of bar soap (Saboori et al., 2010).

Additionally, in February 2011, SWASH+ partners will identify, develop, and pilot school and community monitoring and accountability approaches to understand potential barriers and opportunities. A suitable approach will be piloted in a subset of schools and possibly expanded for formal assessment.

For practitioners interested in reviewing and potentially using our data collections tools, we have shared our materials online (Freeman; Saboori et al. 2010). 
Table 4. Applying lessons learned: A case study

\begin{tabular}{ll}
\hline $\begin{array}{l}\text { Enabling } \\
\text { environment } \\
\text { component }\end{array}$ & Specific issues encountered \\
\hline $\begin{array}{l}\text { Financial } \\
\text { capacity }\end{array}$ & $\begin{array}{l}\text { Insufficient funds for } \\
\text { repurchase of water treatment } \\
\text { products and soap } \\
\text { Insufficient funds for repair } \\
\text { and replacement of containers } \\
\\
\text { and taps }\end{array}$
\end{tabular}

Technical

feasibility

Breakage of taps, containers, and container stands

Theft of soap

Great distance to sources in dry season

Water treatment not carried out correctly

Technical Poor access to repairs availability Poor access to and expense of replacement of inputs

\section{Community SHC inactivity support and student engagement \\ Inadequate community engagement}

School Lack of prioritization and leadership and motivation for WASH accountability Voluntary role of SWS activities in teachers' job description and daily duties
Steps taken toward solutions

Project implementers continue to engage with relevant stakeholders at the school, local, district, and national levels to increase allocation of funds to schools for WASH

Project implementers have incorporated training on budgeting and guidance for allocating adequate funds for soap and water treatment as part of the overall school SWS training activities

Schools have received redesigned stands that are more appropriate for the project, reducing tap breakage A powdered soap/soapy water sub-study was piloted and expanded to address soap theft

Project implementers only targeted schools with adequate access (within $1 \mathrm{~km}$ throughout the year) to implement the SWS in the second year of the project

Project implementers have advocated to government officials for the inclusion of schools in community water projects Refresher courses were provided to year one project schools to ensure water treatment is being correctly conducted

Project implementers plan to train patrons in basic tap repair A division level supply chain to improve access to SWS inputs has been established in three project districts and project implementers are working with local vendors in two additional districts to provide SWS inputs

Project will engage local vendors to purchase additional taps so that school and community members will be able to replace broken taps

Project implementers have held SHC competitions and invited parents to participate

Project implementers trained the SMCs to educate the wider community on SWS activities during parent-teacher days Project implementers have given patrons T-shirts with hygiene messages

Only schools that displayed interest in the SWS were targeted in future rounds of school selections

Project implementers used the child-to-child methodology to help head teachers select appropriate teachers to be patrons and students for the SHCs

Training was also extended to other school and government actors on selection of patrons

\section{Conclusion}

Our evaluation demonstrates that even school-based WASH programmes that report initial successes in improving access may not sustain activities just two to three years following the end of 
Even school-based WASH programmes that report initial successes in improving access may not sustain activities

Implementing organizations need to ensure routine monitoring systems are in place

Programmes must conduct post-final evaluations that can inform best practices programme activities. True project sustainability involves a complex system of inputs and relationships across multiple levels, extending from decisions made at an individual level upwards toward policy created at the government level. While each new intervention will encompass a slightly different set of necessary components to ensure the continuation of benefits beyond the timeline of the intervention itself, it is likely that certain aspects are vital to almost all projects in the school WASH sector.

In our assessment, failure to continue project activities was caused by weaknesses in one or more of the domains we discussed. As schools receiving the WASH interventions do not have control over all aspects of the enabling environment, it is the responsibility of the implementing stakeholders to ensure that all necessary elements are fostered and in place prior to the end of any project. This includes the establishing of funding mechanisms for recurrent costs, whether it is generated by the community or becomes part of the government budget, creating a support network of advocates within the community, and ensuring that the technology is appropriate, affordable, and accessible.

Creating a 'school-based indicators' monitoring system at the school, community, and district levels may be one of the means to improve school WASH conditions (IRC and UNICEF, 2007). To sustain project activities, preconditions and leading indicators that are practical, relevant, and actionable should be identified at project outset. Implementing organizations need to ensure routine monitoring systems are in place and mechanisms exist to identify problems in the system and, more importantly, to solve these problems. Likewise, systems of accountability for school leadership, communities, and local government actors need to be established so that all stakeholders can maintain the components that fall within their sphere of responsibility.

It is our hope that upcoming school WASH programmes can use the lessons learned from this post-final evaluation to develop interventions that beneficiaries are able to sustain for longer periods of time. In order to develop a better understanding of sustainability challenges and successes, programmes must conduct post-final evaluations that can inform best practices and enhance our understanding of the enabling environment.

\section{References}

Bowen, A., Ma H., Ou J., Billhimer, W., Long, T., Mintz, E., Hoekstra, R.M., Luby, S. (2007) 'A cluster-randomized controlled trial evaluating the effect of a handwashing-promotion program in Chinese primary schools', American Journal of Tropical Medicine \& Hygiene 76(6): 1166-73. 
CDC (2000) Safe Water Systems for the Developing World: A Handbook for Implementing Household-Based Water Treatment and Safe Storage Projects (SWS), Centers for Disease Control and Prevention, Atlanta.

Freeman. M.C., Saboori, S., Porter, S., Rheingans, R. (2010) Assessing the sustainability and effectiveness of school WASH projects: a toolkit. Atlanta, GA, USA. Centre for Global Safe Water at Emory University http://www. washinschools.info/docsearch/title/172822

Harnmeijer, J. and Sutton, S. (1993) 'Measuring sustainability in the water sector', Waterlines 12: 28-30.

IRC and UNICEF (2005) Water, Sanitation and Hygiene Education for Schools Roundtable Meeting, Oxford.

IRC and UNICEF (2007) Towards Effective Programming for WASH in Schools: A Manual on Scaling Up Programmes for Water, Sanitation and Hygiene in Schools, TP series, IRC International Water and Sanitation Centre, Delft, the Netherlands.

Mathew, K., Zachariah, S., Shordt, K., Snel, M., Cairncross, S., Biran, A., Schmidt, W. (2009) 'The sustainability and impact of school sanitation, water and hygiene education in southern India', Waterlines 28: 275-92.

Njuguna, Vincent, Karanja, Beth, Thuranira, Mishek, Shordt, Kathleen, Snel, Marielle, Cairncross, Sandy, Biran, Adam, Schmidt, Wolf-Peter (2007) The Sustainability and Impact of School Sanitation, Water and Hygiene Education in Kenya, UNICEF, New York.

Onyango-Ouma, W., Aagaard-Hansen, J., Jensen, B.B. (2005) 'The potential of schoolchildren as health change agents in rural western Kenya', Social Science \& Medicine 61(8): 1711-22.

O'Reilly, C. E., Freeman, M. C., Ravani, M., Migele, J., Mwaki, A., Ayalo, M., Ombeki, S., Hoekstra, R. M., and Quick, R. (2008) 'The impact of a school-based safe water and hygiene programme on knowledge and practices of students and their parents: Nyanza Province, western Kenya, 2006', Epidemiology \& Infection 136: 80-91.

Saboori, S., Mwaki, A., Rheingans, R.D., (2010) 'Is soapy water a viable solution for handwashing in schools?' Waterlines 29(4): 329-36.

Sawamura, N. and Sifuna, D.N. (2008) 'Universalizing primary education in Kenya: Is it beneficial and sustainable?' Journal of International Cooperation in Education 11(3): 103-18.

Sidibe, M. and Curtis, V. (2007) 'Can hygiene be cool and fun? Insights from school children in Senegal', Sanitation and Hygiene Series, WSP, Nairobi.

Snel, M. (2004) The Worth of School Sanitation and Hygiene Education, International Water and Sanitation Centre (IRC), Delft, the Netherlands.

UNICEF (2008) Water, Sanitation and Hygiene Annual Report 2008, UNICEF, New York: 52.

UNICEF (2010) Raising Clean Hands: Advancing Learning, Health, and Participation through WASH in Schools, UNICEF, New York. 